\title{
Tessituras curriculares para os componentes de Física numa perspectiva agroecológica: propostas a partir das experiências pedagógicas no curso da LEdoC no CETENS/UFRB
}

\author{
Frederik Moreira dos Santos ${ }^{1}$, Antônio Carlos Sena Ferreira ${ }^{2}$ \\ 1, 2 Universidade Federal do Recôncavo da Bahia - UFRB. Educação do Campo/CETENS. Avenida Centenário, 697 - Sim, \\ Feira de Santana - BA. Brasil. \\ Autor para correspondência/Author for correspondence: fredsantos@gmail.com
}

\begin{abstract}
RESUMO. O presente trabalho discute práticas pedagógicas de agroecologia utilizadas para o ensino de Física, para licenciandos em Educação do Campo (área de Ciências da Natureza e Matemática), de forma interdisciplinar. Nossas ações reflexivas partiram do contexto das nossas vivências em escolas do campo e no curso de Licenciatura em Educação do Campo na área de Ciências da Natureza, dentro do Centro de Ciência e Tecnologia em Energia e Sustentabilidade da Universidade Federal do Recôncavo da Bahia (CETENS/UFRB). O intuito do texto é propor eixos temáticos curriculares que levem em conta os complexos temáticos discutidos por Moisey Pistrak. Durante a trajetória em nossa caminhada sentimos a necessidade em articular nossa abordagem com a perspectiva teórica freireana, tendo consciência de que, ao exercermos o ofício do magistério, apresentamos um sistema de compreensão sobre a Natureza em sua completude. Os temas propostos em nosso trabalho trazem embutido também a preocupação com a estratégia da abordagem, que balizaram nossas aulas, pois a metodologia, justamente por ser aberta, possui mediação dialógica. As práticas desenvolvidas no Espaço Ecodinâmico do Laboratório Vivo em Agroecologia da UFRB nos serviram como momentos cruciais para reflexão crítica e debate sobre as contribuições advindas dos componentes de Física.
\end{abstract}

Palavras-chave: Ensino de Física, Educação do Campo, Agroecologia, Transdisciplinaridade, Currículo. 


\title{
Curricular seams for disciplines of Physics in an agroecological perspective: proposals from pedagogical experiences at the CETENS/UFRB
}

\begin{abstract}
The present work discusses pedagogical practices of agroecology used to teach Natural Sciences (since of Physics teaching) in the Semiarid region in an interdisciplinary way. Our reflective actions started from the context of our experiences in rural schools, and during the undergraduate course of teaching and learning on Natural Sciences to traditional communities within the Centro de Ciência e Tecnologia em Energia e Sustentabilidade da Universidade Federal do Recôncavo da Bahia (CETENS/UFRB). This paper proposes thematic axis considering the thematic complexes discussed by Moisey Pistrak. During our journey we felt the need to articulate our approach with the Freirean theoretical perspective. Always being aware that, in exercising the magisterium labor, we present a system of understanding on Nature in its wholeness. Upon an open methodology, the topics proposed in our work also include the concern with a strategy of approach shared and discussed with our students, i.e., a dialogic mediation. The practices developed in the Ecodynamic Zone for the Living Laboratory in Agroecology gave us crucial moments to critical reflection and debate on the contributions of the discipline of Physics to traditional communities at CETENS/UFRB.
\end{abstract}

Keywords: Physics Teaching, Rural Education, Agroecology, Transdisciplinarity, Curriculum. 


\section{Tesituras curriculares para los componentes de Física en una perspectiva agroecológica: propuestas a partir de las experiencias pedagógicas en el CETENS/UFRB}

RESUMEN. El presente trabajo discute prácticas pedagógicas de agroecología utilizadas para enseñar de la Física en el Semiárido de forma interdisciplinar. Nuestras acciones reflexivas partieron del contexto de nuestras vivencias en escuelas del campo y en la carrera de Licenciatura en Educación del Campo en área de las Ciencias de la Naturaleza, dentro del Centro de Ciência y Tecnología en Energía y Sustentabilidad de la Universidade Federal do Recôncavo da Bahia (CETENS/UFRB). El propósito del texto es proponer temas que tengan en cuenta los complejos temáticos discutidos por Moisey Pistrak. Durante la trayectoria, sentimos la necesidad de articular nuestro enfoque con la perspectiva teórica freiriana, siempre teniendo conciencia de que, al ejercer el oficio de maestro, presentamos un sistema de entendimiento sobre la Naturaleza en su totalidad. Los temas propuestos en nuestro trabajo incorporan la preocupación con la estrategia del abordaje, que ha anclado nuestras clases, pues la metodología, por ser abierta, tiene mediación dialógica. Las prácticas desarrolladas en el Espacio Ecodinámico del Laboratorio Vivo en Agroecología de la UFRB nos sirvieron como momentos cruciales para reflexión crítica y debate sobre las contribuciones provenientes de los componentes de Física en el transcurso de la carrera de Licenciatura en Educación del Campo.

Palabras clave: Enseñanza de Física, Educación del Campo, Agroecología, Transdisciplinariedad, Currículo. 


\section{Introdução}

O diálogo com o solo começa desde o composto orgânico do vaso de plantas, em escala micro e meso, como em um pequeno canteiro no caminho da entrada da escola, como também na construção, dentro deste mesmo espaço, de agroecossistemas - tendo como sujeitos centrais desta construção a coletividade discente, orientada por monitores e/ou professores. A partir das experiências educativas vivenciadas no Laboratório Vivo em Agroecologia do Centro de Ciência e Tecnologia em Energia e Sustentabilidade - CETENS, durante Estágio Curricular Obrigatório Discente do curso de Licenciatura em Educação do Campo, no Colégio Tecla Mello e das Oficinas do PIBID-Diversidade, discutiremos a implementação de alguns destes agrossistemas e, brevemente, a metodologia de ensino-aprendizagem aplicada neste espaço. Esse Colégio funciona fora do SIM (CETENS), mas ainda recebe alunos do Campo, das comunidades de Jaíba, Lagoa Salgada e do Registro que recentemente foi demarcada como área do perímetro urbano. Por ser uma escola da sede, da mais nova metrópole baiana, que acolhe alunos do Campo, e por estar em frente ao CETENS nos interessamos a trabalhar, e neste espaço escolar temos colaborado para a construção de uma educação pública e de qualidade para os povos do Campo.

Estas reflexões serviram de base para a reformulação da inserção dos componentes de Física no Projeto Pedagógico do Curso de Licenciatura em Educação do Campo, com habilitação em Ciências da Natureza e Matemática, no CETENS/UFRB. Portanto, este texto possui o caráter tanto de um relato de experiência, do grupo do Núcleo Docente Estruturante $(\mathrm{NDE})^{\mathrm{i}}$ articulado com as práticas docentes e discentes, quanto propositivo, que se dirige aos cursos de Ciências da Natureza das LEdoCs, mas que também se constitui e se fundamenta em elementos teóricos mais gerais. Esclarecemos que o presente texto não se propõe a fazer uma discussão exaustiva sobre as teorias, problemáticas e desafios para se implementar um currículo de física para a formação de professores de Ciências da Natureza e Matemática no nível superior para o contexto da Educação do Campo. Porém, ele é fruto da culminância de uma série de debates abertos e reflexões críticas sobre a práxis no ensino dos conteúdos apresentados em diversos componentes de Física no curso de Ciências da Natureza da LEdoC, no CETENS/UFRB. Acreditamos que algumas de nossas conclusões podem 
enriquecer as reflexões em torno do papel dos componentes de Física nesses cursos de formação.

\section{Espaço Ecodinâmico: em que se fundamenta?}

Uma sala de práticas pedagógicas de agroecologia, utilizada para ensinar ciências no Semiárido de forma interdisciplinar e transdisciplinar na escola do campo. Este trabalho é fruto da vivência no curso de Licenciatura em Educação do Campo e dialoga com a perspectiva de uma prática pedagógica articulada com a produção agroecológica. Os licenciandos do Espaço Ecodinâmico dialogaram, o tempo todo, com os conceitos estudados nos Tempos Formativos do LEdoC, o PIBID-Diversidade e o Estágio Curricular Obrigatório do curso, e foi uma das ações do Laboratório Vivo em Agroecologia, no Centro de Ciências e Tecnologia em Energia e Sustentabilidade - CETENS. Todo este contexto formativo sempre leva em conta o mundo do trabalho, onde esta complexidade temática impõe, como método, a transdisciplinaridade. E assim estamos propondo um ensino que busque a mediação de conteúdos e objetivos adequados para a convivência com o Semiárido.

A Agroecologia como ferramenta e a transdisciplinaridade como método de aproximação da realidade para compreensão da vida em contrapartida ao ensino de ciências compartimentalizado. Especificamente pretendemos utilizar a Agroecologia, como ferramenta na contextualização dos conteúdos do livro trabalhado pelo componente curricular de Ciências.

\section{Laboratório Vivo em Agroecologia}

Vivemos em um Estado que tem maior número de agricultores familiares $(M D A)^{i i}$, e que se situa no Semiárido, portanto mostra a importância da existência um polo acadêmico de atividades educativas emancipadoras, que olhe para a convivência com esse ecossistema. Assim, o Laboratório Vivo em Agroecologia vem acumulando desde o seu primeiro momento várias experiências de grande relevância para os sujeitos do Campo em processo de formação. Estas perpassam a práxis pedagógica, onde, para nós da Licenciatura em Educação do Campo - LEdoC, estão diretamente compromissadas com a emancipação dos sujeitos do campo, através de um processo histórico de apropriação do conhecimento, levando em conta as especificidades da Educação do Campo e a Questão Agrária. Todos estes elementos têm norteado as práticas pedagógicas apresentadas aqui.

Estudamos a experiência do Espaço Ecodinâmico do Laboratório Vivo do 
CETENS, imersos em uma reflexão teórica e, a partir desta atividade emancipatória, observamos a necessidade de entender como sistematizar processos educativos que poderão construir o conhecimento, sem descuidar da natureza especificamente contraditória com modelo hegemônico. As práticas desenvolvidas no Espaço Ecodinâmico dialogaram com os saberes tradicionais, modelos de vida, práticas agrícolas, cultura, processos produtivos, sempre aguçando as contradições entre classes.

Do ponto de vista do processo de acumulação do conhecimento, o que se foca é a construção de um ser social histórico, que se entenda através da Agroecologia, para daí enxergar-se de forma cidadã. Um olhar para a formação transformadora, que vai se capacitando num processo, que garanta o domínio dos conteúdos a partir da especificidade do sujeito do campo. Assim, durante o período da colheita do campesinato, podemos perceber uma grande variedade de interações de todas as áreas de conhecimento, observados (pelos sujeitos participantes deste processo de formação e compartilhamento de saberes no espaço Ecodinâmico) materialmente nos produtos colhidos, no sorgo, milho, abóbora, feijão de porco, cana de açúcar, mamona, citronela, batata doce, tomate, hortelã, rúcula, maracujá, coentro, girassol, flor de mel, salsa, melão, PANCs, cebolinha, erva cidreira, capim santo, plantas medicinais, feijão mulatinho, manjericão, plantas ornamentais. Vale destacar que não é agricultura por agricultura, mas um diálogo com o solo codificado, seja através do tamanho da espiga produzida, da quantidade e tamanho dos grãos, do peso da abóbora, da cor da folha, do seu aspecto morfológico e mais uma infinidade de variáveis a serem exploradas. Tudo isso, com a parceria da comunidade acadêmica, e foi-se acumulando, a cada colheita e plantio, os conhecimentos, e a cada passo, o domínio de teorias e práticas de manejo. Esse movimento é emancipador para nós sujeitos do Campo e o Espaço Ecodinâmico é ciclo que se movimenta dialeticamente, nesse espaço formativo entendemos conceitos que trabalharemos na escola do Campo, contextualizamos conteúdos.

\section{Pensando um Programa para a formação de professores do campo: por onde começar?}

O ensino de ciências vem passando por constantes modificações, sobretudo depois das discussões em torno da Base Nacional Comum Curricular - BNCC, que têm polemizado o currículo escolar na educação básica brasileira. A despeito do fato desse tema não ser nosso foco neste 
texto, é bom lembrar que a maioria do povo brasileiro ainda nem assimilou esse processo.

O nosso enfoque traz embutido as reflexões das pesquisas em Educação do Campo na área de Ciências da Natureza com um olhar para o ensino de Física em especial, e nos propusemos a apresentar a proposta de um tema central (i.e. os princípios de conservação de massa e de energia) conectado com a Física nas visões fenomenológicas, valorizando o solo para o sujeito do campo, considerando em primeiro lugar o papel preponderante da relação homem-natureza.

Assim pretendemos construir um programa sugestivo de Física orientado pela agroecologia, e que tenha um olhar para a "Escola do Trabalho" (Pistrak, 2003), e o tema "Recuperação do Solo" pensado nas matrizes dos conhecimentos tradicionais, desde as interações astronômicas, químicas, biológicas, e as físicas com olhar para atmosfera, litosfera, e hidrosfera, em que poderemos trabalhar os conceitos e as leis naturais, buscando compreender as transformações de energias, a interação da matéria, e antes de tudo, caminharmos no sentido que caminha o estudante do campo, na hora de preparar a aula. Este trabalho acadêmico propõe a explorarmos, em nossas práticas pedagógicas, o conceito de complexos temáticos e um currículo que dialogue com as práticas de subsistência e significativas de uma comunidade como perspectiva que dê conta de balizar as nossas ações inspiradas na pedagogia socialista de Pistrak. Alguns destes elementos teóricos da pedagogia socialista estarão presentes no decorrer deste artigo.

Um solo fértil é o capital do camponês, é a partir daí que o mundo do trabalho entra em sintonia com o programa de ensino, e se o conteúdo for problematizado aproximando-se da vida do estudante, todos ganharão e o desenvolvimento acontece.

Este programa tem $\mathrm{o}$ intuito propositivo para cursos de Licenciatura em Educação do Campo, nas áreas de Ciências da Natureza e Matemática, no intuito de buscar formar um contingente de professores que consequentemente interfiram na construção dos currículos que são construídos para as escolas do Campo. Tomamos aqui, a formação dos professores nos cursos de licenciatura em Educação do Campo como um dos principais vetores para a transformação das Escolas do Campo.

\section{Tópicos programáticos}

Nossa sistematização curricular se organizou em torno de experiências que se aproximam de certos eixos temáticos. Para 

propostas a partir das experiências pedagógicas no curso da LEdoC no CETENS/UFRB...

os sujeitos do Campo, principalmente do semiárido, os ciclos do Sol e da Lua e suas relações com os ciclos do clima e da vida são os eixos estruturantes destas experiências, mesmo entre indivíduos de zonas urbanas que trabalham diretamente com outros setores que não envolvem a vida no Campo. Por isso, pensamos nestes tópicos programáticos desta maneira abaixo, pois integram ações e fenômenos da vida do Campo a partir de dois grandes eixos estruturantes de todo o conteúdo teórico da Física: os princípios de conservação de massa e de energia.

\section{Ciclo da água e ciclos energéticos}

i. Medidas, Movimento linear, Leis de Newton (tecnologias sociais do Campo;

ii. Massa, peso, campo gravitacional;

iii. Momento Angular e Torque (tecnologias sociais do Campo);

iv. Trabalho e Energia;

v. Fluidodinâmica, e Transporte de Energia com e sem Matéria (Comunicação e tecnologias sociais do Campo);

vi. Calor, fontes de energia, e ciclos termodinâmicos (Tipos);

vii. Radiação solar (O Sol, pensado também como sistema acoplado termodinamicamente ao sistema terrestre).
Essa sequência, que será mais detalhadamente desdobrada no decorrer deste artigo, foi pensada a partir de uma preocupação com as experiências cotidianas mais significativas e norteadoras para as nossas ações em sala de aula, após a reflexão coletiva, com os estudantes do LEdoC do CETENS-UFRB, sobre a prática docente. Antes de avançarmos em nossa proposta, vale destacar um breve esclarecimento teórico. A força daquilo que chamamos de "experiências significativas" é dada pela recorrência destas na vida e na sua subsistência. Tais experiências ajudam a construir a visão que se tem sobre o próprio conceito de Natureza (com todas as suas dimensões, tanto biológica, quanto social e psíquica), tanto em torno desta, como em conjunto com esta. A partir desta significação se constroem culturas com suas linguagens, i.e., ritos e festas, artesanatos, léxicos, etc. Defendemos, dentro de um viés teórico freireano (Delizoicov, 1983), que um ensinoaprendizagem com criticidade deva partir das experiências mais significativas de um povo, assim como da consciência de sua condição humana na teia social que hierarquiza e desumaniza uns em prol da sustentação do privilégio de outros.

Quando ensinamos apresentamos, em certa medida, um novo sistema de entendimento sobre a Natureza em sua 
completude (ou visões de mundo). Porém, acreditamos que deveríamos fazê-lo levando em conta o sistema ou os sistemas de crença já constituídos dentro de um coletivo de estudantes que representam diferentes formas de vida, dado que o respeito à soberania dos povos é respeitar também as suas formas de pensar a Natureza. Por isso, defendemos a importância de se buscar o entendimento e compreensão dos conteúdos de ciências em prol da melhoria da vida no Campo, dos instrumentos utilizados e da consciência cidadã das pessoas do campo (minimizando a sua alienação). Não defendemos uma compreensão de qualquer natureza, porém aquelas comprometidas com ações de intervenção na realidade que os cerca e os constitui. Este posicionamento nos afasta de uma concepção colonizadora do ensino de ciências, pois falar de entendimento e compreensão não envolve necessariamente crença e aceitação. Nosso compromisso é com a ação e a abertura ao diálogo, não queremos anular a possibilidade que os sujeitos tenham de mudanças de crenças no decorrer do processo, só não defendemos que este deve ser o fim do processo de ensino-aprendizagem (Moreira-dos-Santos \& El-Hani, 2017).
Sugestão metodológica para desenvolver o programa aqui proposto: retalhos de sua gênese

O tema Recuperação do Solo proposto em nosso trabalho traz embutido também a preocupação com a estratégia da abordagem, que balizou nossas aulas (a pedagogia socialista de Pistrak), pois a metodologia, justamente por ser aberta, possui mediação dialética. Pensamos em uma metodologia que possa ser aplicada para o planejamento de uma aula ou até mesmo para cada unidade de Física (com seu tempo escola e comunidade). Assim, sistematizamos este direcionamento da seguinte maneira:

a) A localização do sujeito: para que cada um perceba-se em seu geossistema, o chão que nós pisamos;

b) A problematização: que vem aguçando as contradições existentes para cada um, e os conceitos trabalhados pelo professor tragam nesse momento $\mathrm{o}$ raciocínio crítico do aluno, incrementando aqui pela nossa proposta o grande e mais importante debate sobre os conhecimentos tradicionais, que devem ser estimulados, não como dicotômicos, mas sim como norteadores da contextualização dos conceitos da Física;

c) A sistematização do pensamento: aqui construímos a organização dos comparativos e das classificações (Ex. 
tipos de solos, interações que resultam em mudanças de estados etc);

d) A produção: onde agora poderá acontecer o protagonismo, a generalização se apresenta de forma prática, em que cada um, coletivamente ou individualmente, construirá a experimentação, a práxis, a realização do seu trabalho científico. Nesse item, entendemos ser o melhor momento para lembrarmos da experiência crucial no LEdoC - CETENS/UFRB, o qual durante as aulas do componente de Física, Recursos Naturais III (componente do antigo Projeto Político-Pedagógico do curso de LEdoC, com ênfase em Ciências da Natureza), a construção do conhecimento se deu de forma dialógica. Os conceitos de Física foram trabalhados, durante este componente e durante aqueles que se seguiram, conforme o método aqui proposto, garantindo um maior tempo pedagógico aos sujeitos envolvidos no processo educacional, na localização, problematização, sistematização e a produção. A partir deste componente, o diferencial ficou notório, pois a produção científica aconteceu de forma coletiva, e claramente afirmativa de cada um. Na última fase do componente, os conceitos trabalhados vieram à tona, tivemos protótipos espalhados no pátio do CETENS, explicações fenomenológicas dos processos trans e interdisciplinares ali foram visualizadas por todos, foi um momento emblemático, gratificante tanto para os estudantes do LEdoC, quanto para os professores, e os visitantes que puderam testemunhar o mundo da Física ao vivo, desde o Efeito Fotoelétrico às Leis da Termodinâmica. Com esta atividade, construídas coletivamente, buscou-se impactar a prática docente no curso, e por conseguinte na formação dos sujeitos envolvidos no projeto. A própria metodologia do curso foi construída em conjunto com os discentes do componente;

e) Nova sistematização: Este é o momento para sistematizarmos todo $\mathrm{o}$ caminhar, costurar as tessituras dando diferentes possibilidades de registro, diferentes meios de costura. Sugerimos a construção de um relatório, podendo ser escrito com a utilização de desenhos, onde o discente deverá descrever a atividade a partir daquilo que foi aprendido durante todo o processo, não esquecendo de enfatizar os momentos de dificuldade, erros e barreiras, e qual estratégia utilizou para superá-los. Dificuldades podem levar à(s) mudança(s) no planejamento, e estas não devem ser deixadas de lado. Este é um momento para se focar mais no processo de realização da atividade e das estratégias cognitivas utilizadas, e a tomada de consciência crítica em relação a estas 
estratégias, do que em resultados esperados.

\section{O programa proposto}

Dentro de nossa perspectiva metodológica não poderíamos deixar de pensar uma forma desatrelada do conteúdo, pois assim compreendemos ser uma dimensão crucial da experiência da práxis pedagógica. Sendo o currículo como o meio material e concreto de uma convergência de intenções e ideologias, o currículo tradicional de Física não poderia passar imaculado. Frequentemente, se pensa em componentes de Física Básica tendo em vista as disciplinas dadas no ensino médio, assim são pensados os cursos de licenciatura em Física e Ciências da Natureza no Brasil, parte-se da mesma sequência de assuntos e tópicos (com poucas variações na grande maioria dos livros e cursos), ou seja: leis de Newton e suas aplicações, Energia Mecânica, Calorimetria e Termodinâmica, Ótica, Eletricidade e Magnetismo, Eletromagnetismo, Radiação, Física Moderna: introdução à Física Quântica e à Relatividade. Sem deixar de oportunizar aos nossos estudantes do Campo o acesso ao conhecimento científico fundamental para a formação contemporânea, propomos algumas mudanças de enfoque e eixos temáticos (já apresentados acima) que possam facilitar a contextualização. Assim, permitiremos um diálogo e encaixe mais fluido entre a metodologia apresentada acima a partir do conteúdo proposto. Acrescentamos tópicos normalmente não vistos na formação de professores de Física para o ensino médio, e que são cruciais para os povos do Campo, e retiramos certos enfoques de conteúdo (inclusive o peso exagerado dado à modelização matemática, a ponto de se deixar de lado a importância da compreensão dos conceitos científicos) que pouco dialogam com esta realidade. Porém, nada disso comprometeu a apropriação, por parte dos professores em formação, dos princípios físicos fundamentais para a compreensão deste campo disciplinar. Assim, pautados nesta preocupação trans e interdisciplinar, nos princípios da Educação do Campo e na preocupação com a contextualização que estes tópicos abaixo foram pensados durante a reformulação do Projeto Político Pedagógico do curso da LEdoC CETENS/UFRB as seguintes temáticas gerais que direcionaram o conteúdo das ementas de Física:

I. Medidas, Leis de Newton e trabalho para a questão agrária: $\mathrm{O}$ território, seus limites e constituição, como referencial conceitual para construir o espaço abstrato. Medidas agrárias do SI, no entendimento do que é 
minifúndio e latifúndio, e do ponto de vista de um laboratório de Física, a nanometria para concepção teórica da constituição da matéria. Esse conjunto de mensuráveis unidades são importantes para comparações científicas, tendo em vista que o conceito de espaço e tempo são fundamentais para a compreensão das leis de Newton e dos movimentos presentes na Física dos solos, transporte e equilíbrio de cargas, utilização de roldanas, etc. Assim, a Física poderá trazer uma importante contribuição para o aprofundamento do conceito de território, investigando a sua dimensão abstrata e material.

II. Massa, Peso e Campo Gravitacional: esses conceitos teóricos serão retomados e ajudarão a teorizar cada vez mais o diálogo com a agroecologia, pois são básicos $\mathrm{e}$ perpassa por leis importantíssimas da Física. Nesse caso, poderemos viajar pelo princípio da preservação do solo e da sua fertilidade, uma vez que entendemos que sua fertilidade é o capital do camponês, mas, para tanto, é preciso que a escola do Campo possa garantir o ensino significativo para o contexto do labor camponês. Tal posicionamento é um dos pilares da escola do trabalho, que nos permite evidenciar no processo educacional, construído em conjunto com a experiência campesina, que a compactação (e o aumento de sua densidade), é talvez a grande vilã da vida microbiana do solo. A importância da gravidade para a constituição das chuvas. Devemos estudar leis universais como a da gravitação, para ligar aos conhecimentos tradicionais - como, por exemplo, a atração na interação entre o sistema Terra - Lua que ajudará a responder a algumas indagações levantadas pelas pessoas do campo, tais como: Por que a Lua parece variar de tamanho? Por que ocorrem os eclipses e as fases da Lua? Como a Lua pode influenciar nos ciclos da vida na Terra e nas plantações?

*O Núcleo Docente Estruturante (NDE) do LEdoC, no CETENS-UFRB, em debate com sua comunidade, reformulou o componente "Terra e Universo" (carga horária de 34 horas) ${ }^{\text {iii }}$ para dar conta deste conteúdo e dos modelos cosmológicos contemporâneos.*

*O componente "Física e Tecnologias Sociais I: mecânica newtoniana" (carga horária de 68 horas) foi criado 
Santos, F. M., \& Ferreira, A. C. S. (2020). Tessituras curriculares para os componentes de Física numa perspectiva agroecológica: propostas a partir das experiências pedagógicas no curso da LEdoC no CETENS/UFRB...

para dar conta tanto do primeiro item quanto para introduzir o conceito de força que será visto também no componente de "Terra e Universo".*

III. Momento Angular, Torque $e$ tecnologias do Campo: é um conteúdo que normalmente não aparece para os alunos do ensino médio, mas que exerce papel fundamental no Campo, pois várias ferramentas e maquinários se utilizam de fenômenos que envolvem torque, desde o movimento da enxada, a sua aplicação em uma casa de farinha, até o funcionamento de uma alavanca presente em bombas d'agua e arados.

*Os conceitos "momento angular e torque" na física são explorados na segunda metade do componente "Física e Tecnologias Sociais I: mecânica newtoniana" (carga horária de 68 horas).*

*Modificamos o foco que o ensino tradicional dá em relação às aplicações da segunda lei de Newton (tais como: máquinas de Atwood e plano inclinado), dedicamos mais tempo para o estudo do uso de roldanas para o deslocamento vertical de cargas e as aplicações do conceito de torque, dado que estes são os de aplicação mais frutífera em relação aos instrumentos e tecnologias utilizadas pelos povos do Campo.*

IV. Energia Mecânica, Fluidodinâmica e Transporte de Energia com Matéria: são importantes para construção da ponte entre Agroecologia e Ensino de Física, pois pode ser utilizado para iniciar o entendimento do funcionamento dos instrumentos utilizados tanto para o cultivo quanto para a colheita, e a sua acomodação no Agroecossistema deverá ser tratada e visualizada na prática cotidiana. A água é o elemento principal para a construção do conhecimento dos princípios da agroecologia, onde o manejo do solo e o uso sustentável da água na irrigação, sobretudo no semiárido, precisa ser notório na prática pedagógica. Uma transposição didática conceitual da equação da continuidade e, se possível, da equação de Bernoulli, pode ser de grande valia para o aprofundamento destas questões, mostrando o papel e a importância dos sistemas ideais na teorização do conhecimento físico para aproximar do estudo dos fluidos reais. Acreditamos que este seria o melhor momento para aplicarmos nos fluidos os estudos mais 
Santos, F. M., \& Ferreira, A. C. S. (2020). Tessituras curriculares para os componentes de Física numa perspectiva agroecológica: propostas a partir das experiências pedagógicas no curso da LEdoC no CETENS / UFRB...

fundamentais sobre os processos de irrigação e flutuação, conceitos fundamentais, porém não suficientes para se compreender o processo de assoreamento e geomorfologia dos leitos e relevo dos rios.

*O componente "Física dos Sistemas Mecânicos" (carga horária de 68 horas) é dedicado ao princípio da conservação da energia mecânica na primeira parte do componente, seguido dos estudos sobre hidrostática e introdução a hidrodinâmica.*

V. Calor e Energia Térmica (estados da matéria e as leis da termodinâmica): sem direcionar só para a questão das suas métricas - entendemos que no programa aqui proposto as interações atmosféricas vão além de um movimento de massas de ar e vapor de água, ou coisa desse tipo, para o diálogo com a agroecologia no ensino de ciências. O solo, a água, o ar, e o vento, com sua dinâmica de deslocamento e transformações, estão contidos no cerne da construção do conhecimento. A ação do calor e da mudança de temperatura são centrais para o entendimento de tais transformações. Os ciclos biogeoquímicos vão fazer o link com as interações e transformações naturais, olhando para a matriz produtiva agroecológica, pois a ciclagem de nutrientes, a sua transmutação com baixa energia dispensada, são enfoques conceituas que podem aprimorar a prática de conservação dos solos dos camponeses. Tal fato é central para tratar da importância da conservação do solo, é questão de fundo, e é, também, estratégico para o uso da agroecologia no ensino de ciências no semiárido. Lembremos do processo da compostagem, que é um efeito macroscópico, e na fotossíntese, microscópico.

*Inserimos no fluxograma do curso o componente "Física dos Sistemas Térmicos" (carga horária de 68 horas) com uma ementa voltada, principalmente, ao conteúdo da termodinâmica tendo em vista um diálogo concomitante com o componente de "Fundamentos de Química II" (carga horária de 68 horas), onde será estudado o conteúdo de termoquímica.*

VI. Radiação Solar e as Interações da Matéria: pensaremos com os pés no campo, e sobretudo no semiárido, olhando de forma problematizadora a partir de sua constituição mais fundamental, ou seja, a matéria, suas 
interações entre si e com a radiação, tais como: o sol e seus efeitos no solo, na atmosfera e nos organismos que neles habitam, na evaporação da água e nas plantas. Assim, dar-se-á visibilidade a ação agroecológica, pela sua importância na compreensão da fotossíntese para os vegetais, e a conservação do solo pela sua proteção propriamente dita. A interação que queremos enxergar aqui é o que acontece aparentemente invisível, mas não é. Aliás, muito pelo contrário, tem escala meso e macroscópica em seus efeitos biofísicos, nos fenômenos de evaporação, transpiração, temperatura etc. Neste momento podemos tratar da compreensão quântica de radiação e de sua aplicação na fotossíntese e nas células fotovoltaicas. As interações entre radiação e matéria, através dos raios cósmicos, e seus efeitos na biomassa, na atmosfera e no solo são, para nós, a base para trabalhar os complexos temáticos, i.e., muitos conceitos físico-químico-biológicos de forma efetivamente integrada e transdisciplinar, e são responsáveis pelas transformações nos processos físicos, e são facilmente observados no nosso cotidiano.
*O componente "Física e Tecnologias Sociais II (carga horária de 51 horas)", através do qual se verá o conteúdo de eletromagnetismo, foi criado com o intuito de discutir a formação das partículas e suas interações e as formas de produção energética, comunicação por ondas eletromagnéticas e seu impacto no meio ambiente. A história do papel dos estudos dos raios cósmicos na inserção dos primeiros centros brasileiros de pesquisa em Física no cenário internacional pode nos fornecer um rico cenário a ser explorado na sala de aula. Os conteúdos de capilaridade (xilemas e estômatos) nos vegetais e tensão superficial poderão ser vistos como aplicações da eletrostática. Esse componente ajudará a aprofundar o diálogo com o conteúdo dos "Fundamentos da Química I e II" (ambos com carga horária de 68 horas) e como introdução para "Fotofísica" (carga horária de 51 horas).*

* O NDE, por sugestão do docente de Física, propôs um componente chamado "Fotofísica" (transporte de energia sem matéria) para trabalhar o conceitos de ondas eletromagnéticas, assim como suas interações com a 
matéria e o surgimento da Física Quântica e seu papel para a compreensão do efeito fotoelétrico, tão importante para a investigação do fenômeno da fotossíntese e o funcionamento das células fotovoltaicas.*

\section{Comentários finais}

A despeito de nosso foco, neste artigo, ter sido em torno dos componentes das Físicas Básicas, vale ressaltar que tanto os conteúdos de Física, quanto de Biologia, foram estruturados em nosso Projeto Político-Pedagógico do Curso de Licenciatura em Educação do Campo, no CETENS-UFRB, partindo de uma visão sistêmica macroscópica da Natureza e mais próximos das escalas utilizadas em nosso cotidiano, para sistemas microscópicos. É no campo da escala meso das experiências do campesinato que tessituras contextuais mais efetivas podem ocorrer, pois é nesta escala que o mundo da vida no Campo se desdobra de forma mais afetiva e mnemônica. Isso torna ainda mais desafiador o diálogo entre os campos disciplinares, pois não é seguindo esta direção na escala estrutural (do meso e macro para o micro) que, normalmente, os outros campos das Ciências Naturais são organizados. No entanto, além das "Práticas Pedagógicas" (carga horária de
68 horas cada uma), outros componentes, tais como, "Elementos de Geociências" (carga horária de 51 horas) e "Agroecologia II" (carga horária de 34 horas) têm nos auxiliado nesta integralização trans e interdisciplinar. Dessa forma, lançamos mão dos complexos temáticos (Pistrak, 2003) demandados pela própria realidade do Campo.

Esse perspectivismo e a visão sistêmica e cíclica dos conteúdos das Ciências Naturais vão se evidenciando ainda mais a partir da quarta etapa do curso através de componentes integradores, tais como: "Física dos Sistemas Térmicos", “Terra e Universo", "Genética e Evolução Biológica" (carga horária de 51 horas) e "Fundamentos da Química II". Os componentes de "Agroecologia II" e "Elementos de Geociências" aparecem na sétima etapa como o ponto culminante desta busca da integralização dos conteúdos em direção a um maior aprofundamento dos sistemas agroecológicos. Esta é uma busca que a reforma das nossas ementas, PPC e fluxograma, não será suficiente para garantir o alcance dos nossos objetivos finais, ou seja, a articulação dos conteúdos das Ciências da Natureza em torno de um eixo estruturante que são os sistemas agroecológicos no semiárido brasileiro. 

propostas a partir das experiências pedagógicas no curso da LEdoC no CETENS/UFRB...

Faz-se necessário, também, o compromisso político e formativo dos docentes com esta aproximação com o conhecimento agroecológico.

Acreditamos que o conhecimento supracitado trará maior tomada de consciência dos processos naturais em que a terra é e pode ser submetida, de forma a respeitar a preservação da diversidade do seu próprio bioma e dos sujeitos que dele fazem parte. Conhecimento tal, que desejamos que faça diferença para a ação das pessoas do Campo em torno da terra e da vida que sobre ela e debaixo dela se sustenta (Caldart, 2015).

O espaço ecodinâmico do Laboratório Vivo coordenado pela educadora e geógrafa Dra. Silvana Lucia da Silva Lima (do corpo docente da LEdoC-CETENS) e gerenciado em conjunto com os próprios alunos, para além de um espaço formativo em agroecologia, nos serviu como um dos momentos cruciais para reflexão crítica e debate sobre as contribuições advindas dos componentes de Física dentro do curso da LEdoC-CETENS/UFRB.

Como fonte bibliográfica para trabalhar estes conteúdos voltados mais para o contexto do Campo temos indicado uma variedade de bibliografias básicas para auxiliar nos estudos complementares, tanto dos alunos quanto dos professores, porém o livro dos autores Okuno, Caldas e Chow (1986) é o que tem nos servido mais frequentemente como referência para dialogar com a química e a biologia. Nossa forma de estruturar os eixos possui inspiração também no livro escrito por Delizoicov e Angotti (1990), onde apresentam uma proposta metodológica, de inspiração freireana, para sistematizar o currículo e a práxis do ensino de Física no Ensino Médio.

Por fim, acreditamos ser de grande ajuda apresentarmos, inicialmente, os conteúdos da Física dentro do contexto do seu surgimento histórico, porém não devemos nos esquecer que existem diversas formas de se apresentar um conteúdo científico a partir da perspectiva de sua história social e conceitual (Freire, 2002, Martins, 1990). Defendemos que algumas perguntas poderiam disparar uma reflexão crítica sobre o conteúdo apresentado, de forma a contribuir para a sua compreensão de maneira mais humanizada. As perguntas que nos referimos são: Quais foram as condições materiais que levaram a surgir o interesse e aprofundamento dos estudos do movimento na Europa, principalmente Itália e Inglaterra, do séc. XVI e XVII? Como a sociedade se organizava em torno da cultura material que demandou um interesse no cálculo das distâncias, 
construção de mapas, rápido deslocamento e construção de armamentos? Como isso impactou no estudo do movimento e das causas do movimento? Perguntas semelhantes podem ser transpostas para os conteúdos de termodinâmica e para o surgimento da teoria quântica.

Todas estas investigações e campos disciplinares surgiram em torno de interesses e demandas práticas relacionadas de alguma forma com a organização social em torno de uma certa cultura material. E a partir de um certo tempo, estas demandas e culturas materiais, passaram a ser regidas pela dinâmica econômica capitalista. Um outro viés histórico a ser explorado que está conectado com as condições materiais de cada tempo e sociedade é o papel que as controvérsias científicas exercem no desenvolvimento e evolução conceitual dos campos disciplinares e instituições científicas. Autores brasileiros tais como Abrantes (2016), Freire (2015, 1993, 1991), Martins (2010, 2008, 2007) e muitos outros historiadores brasileiros, têm trazido grandes contribuições para a elucidação destas controvérsias no campo da Física.

Estas discussões históricas e sociais ajudarão para o amadurecimento teórico e político de uma das colunas vertebrais do pensamento agroecológico e dos próprios fundamentos da Educação do Campo, i.e., o materialismo dialético. Eixo teórico central para a compreensão da dinâmica das lutas e das histórias construídas a partir das contradições da realidade do campo. Segundo Pistrak:

Estuda-se a realidade atual pelo conhecimento dos fenômenos e dos objetos em suas relações recíprocas, estudando-se cada objeto e cada fenômeno de pontos de vista diferentes. $\mathrm{O}$ estudo deve mostrar as relações recíprocas existentes entre os aspectos diferentes das coisas, esclarecendo-se a transformação de certos fenômenos em outros, ou seja, o estudo da realidade atual deve utilizar o método dialético. (2003, p. 134).

Assim, iremos potencializar a possibilidade de se compreender melhor as dimensões políticas, econômicas, estéticas, e axiológicas da realidade social em que o labor científico está inserido e foi constituído, e ao mesmo tempo, como os obstáculos que os povos do Campo têm tido para produzir as suas próprias Ciências (Souza \& Martins, 2013).

\section{Referências}

Abrantes, P. (2016). Imagens da natureza, imagens de ciência. Rio de Janeiro: EdUERJ.

Caldart, R. S. (fevereiro de 2016). Escolas do campo e Agroecologia: uma agenda de trabalho com a vida e pela vida! Veranopolis - RS (mimeo). 
Delizoicov, D. (1983). Ensino de física e a concepção freiriana da educação. In Revista de Ensino de Física, 5(2).

Delizoicov, D., \& Angotti, J. A. (1990). Física. São Paulo: Cortez.

Freire Jr., O. (2015). Das margens para o centro: Mudanças na pesquisa em fundamentos da mecânica quântica, 19501990. Caderno Brasileiro de Ensino de Física (Online), 32, 369-377. https://doi.org/10.5007/21757941.2015v32n2p369

Freire Jr., O. (2002). A relevância da Filosofia e da História das Ciências para a formação dos professores de ciências. In Silva Filho, W. J. (Org.). Epistemologia e Ensino de Ciências (pp. 13-30). Salvador: Arcadia.

Freire Jr., O. (1993). Sobre as raízes sociais e econômicas dos princípios de Newton. Revista da Sociedade Brasileira de História da Ciência, 9, 51-64.

Freire Jr., O. (1991). Sobre as desigualdades de Bell. Caderno Catarinense de Ensino de Fisica, 8(3), 212-226.

Martins, R. A. (2010). Espaço, tempo e éter na teoria da relatividade. In Knobel, M., \& Schulz, P. A. (Orgs.). Einstein: muito além da relatividade (pp. 31-60). São Paulo: Instituto Sangari.

Martins, R. A. (2008). A herança de Sacrobosco e seus comentadores: desenvolvimentos e erros na astronomia geocêntrica do século XVI. In Martins, R. A., Silva, C. C., Ferreira, J. M. H., \& Martins, L. A. P. (Orgs.). Filosofia e História da Ciência no Cone Sul. Seleção de Trabalhos do $5^{\circ}$ Encontro (pp. 373382). Campinas: Associação de Filosofia e História da Ciência do Cone Sul (AFHIC).
Martins, R. A. (2007). Os "raios $N "$ de René Blondlot: uma anomalia na história da física. Rio de Janeiro: Booklink; São Paulo: FAPESP; Campinas: GHTC. (Scientiarum Historia et Theoria, vol. 3).

Martins, R. A. (1990). Sobre o papel da História da Ciência no ensino. Boletim da Sociedade Brasileira de História da Ciência, 9, 3-5.

Moreira-dos-Santos, F., \& El-Hani, C. N. (2017). Belief, Knowledge and Understanding. Science \& Education (Online), 26, 215-245. https://doi.org/10.1007/s11191-017-9891-5

Okuno, E., Caldas, I. L., \& Chow, C. (1986). Física para Ciências Biológicas e Biomédicas. São Paulo: HARBRA.

Pistrak, M. M. (2003). Fundamentos da escola do trabalho. São Paulo: Expressão popular.

Sousa, R. P., \& Martins, S. R. (2013). Construção do conhecimento agroecológico: desafios para a resistência científico-acadêmica no Brasil. In Costa Gomes, J. C., \& Assis, W. S. (Orgs.). Agroecologia: princípios e reflexões conceituais (pp. 73-108). Brasília: EMBRAPA.

\footnotetext{
i Projeto do "Laboratório Vivo: núcleo de Agroecologia e Educação do Campo" financiado pelo edital no. 12/2016 - Agroecologia/2016.

${ }^{\mathrm{i}}$ No qual o autor principal preside.

${ }^{\text {ii }}$ Fonte: Jornal Bahia Online (17 de Abril de 2013). Bahia é o estado com o maior número de agricultores familiares do Brasil. Disponível no endereço:

http://www.jornalbahiaonline.com.br/noticia/22213/ bahia_e_o_estado_com_o_maior_numero_de_agric ultores_familiares_do_brasil

iii Todas as informações sobre a carga horária presentes neste artigo compreendem o Tempo
} 
Santos, F. M., \& Ferreira, A. C. S. (2020). Tessituras curriculares para os componentes de Física numa perspectiva agroecológica: propostas a partir das experiências pedagógicas no curso da LEdoC no CETENS/UFRB...

Universidade $(\sim 70 \%$ do total $)$ e o Tempo Comunidade ( $30 \%$ do total $)$.

\section{Informações do artigo / Article Information}

Recebido em : 18/12/2018

Aprovado em: 22/03/2019

Publicado em: 07/05/2020

Received on December 18th, 2018

Accepted on March 22th, 2019

Published on May, 07th, 2020

Contribuições no artigo: Os autores foram os responsáveis por todas as etapas e resultados da pesquisa, a saber: elaboração, análise e interpretação dos dados; escrita e revisão do conteúdo do manuscrito e; aprovação da versão final publicada.

Author Contributions: The author were responsible for the designing, delineating, analyzing and interpreting the data, production of the manuscript, critical revision of the content and approval of the final version published.

Conflitos de interesse: Os autores declararam não haver nenhum conflito de interesse referente a este artigo.

Conflict of Interest: None reported.

Orcid

Frederik Moreira dos Santos

(iD) http://orcid.org/0000-0001-8038-147X

Antônio Carlos Sena Ferreira

http://orcid.org/0000-0002-7141-3350

\section{Como citar este artigo / How to cite this article}

APA

Santos, F. M., \& Ferreira, A. C. S. (2020). Tessituras curriculares para os componentes de Física numa perspectiva agroecológica: propostas a partir das experiências pedagógicas no curso da LEdoC no CETENS/UFRB. Rev. Bras. Educ. Camp., 5, e6297. http://dx.doi.org/10.20873/uft.rbec.e6297

\section{ABNT}

SANTOS, F. M.; FERREIRA, A. C. S. Tessituras curriculares para os componentes de Física numa perspectiva agroecológica: propostas a partir das experiências pedagógicas no curso da LEdoC no CETENS/UFRB. Rev. Bras. Educ. Camp., Tocantinópolis, v. $5, \quad$ e6297, 2020. http://dx.doi.org/10.20873/uft.rbec.e6297 